\title{
Predictors of Academic Performance: An Assessment of Secondary Students' Mathematical Ability
}

\author{
Elymar A. Pascual \\ elymarpascual@rocketmail.com \\ Department of Education, Nagcarlan, Laguna, Philippines, 4002
}

\begin{abstract}
This study is a sequel to last school year's study on assessment of the Mathematical ability of private school students. In that study, data showed that a private school students have a knowledge ability level of $84.28 \%$, comprehension ability level of $82.58 \%$, and application ability level of $77.57 \%$, resulting to a Mathematical performance of $81.19 \%$. Using Multiple Regression Analysis, results showed that the application ability of the student was the highest predictor of his Mathematical performance, while the comprehension ability of the student was the least predictor his Mathematical performance. While the previous paper focused on the three level of thinking skills (knowledge, comprehension and application), this present one includes the fourth in the Bloom's Taxonomy - analysis. Grade 5 students are also included as additional to last school year's grade 6, 9 and 10 students. The researcher repeated the process of knowing the mean level of Mathematical ability, noting the significant effect of those abilities to the Mathematical performance, and finding out the predictability of the Mathematical performance of the private high school students. Results revealed that a private school students have a knowledge ability level of $82.11 \%$, comprehension ability level of $82.29 \%$, application ability level of $75.86 \%$, and analysis ability level of $77.51 \%$, giving a Mathematical performance of $79.07 \%$. Using Multiple Regression Analysis, results supported the findings last school year that the application ability of the student is the highest predictor of his Mathematical performance, while the knowledge ability of the student came out to be the least predictor of his Mathematical performance.
\end{abstract}

Keywords: Mathematical performance; Mathematical ability; knowledge; comprehension; application; analysis

\section{Introduction}

Just a few months ago, President Gloria Macapagal-Arroyo announced to the public that the Department of Education has just attained the objective of raising the mathematical and science ability of the Filipino students. And so the Philippine government will now focus on the English proficiency of the Filipinos, adding more budget on Philippine Education. "The budget of the Department of Education (DepEd) was increased by P5.273 billion from an original allocation of P145.975 billion..." (Mar. 28, 2008, Education Department..., Manila Times)

But how true is it that we have already solved the problem in Philippine education in terms of math and science achievement? Recent report from www.Save_the_Children@yahoo.com (2008) said that on the average, only 43 percent of the required English, Science and Math competencies are mastered by Filipino pupils. This data is in line with the result of Trends in International Mathematics and Science Studies (TIMSS) last 2003 wherein we landed $41^{\text {st }}$ in Mathematics out of 45 participating countries, beating Botswana (42), Saudi Arabia (43), Ghana (44) and South Africa (45). The top five were Singapore, South Korea, Hong Kong, Chinese Taipei and Japan.

The study made by TIMSS happens every four years. Last year 2007, they again conducted an international examination. From 45 participating countries last 2003, the number of participating countries increased to more than 70, and surprisingly the Philippines did not sign up. The result will be revealed this year in leading newspapers and electronic media. What if the Philippines signed up for this study? In what place shall we land off? Will our students do the same four years ago, or will they do better? 

so that our students will rise above the international average and be able to make up with our regretful status in international exams?

\subsection{Background of the Study}

This paper is a follow-up of last school year's research on assessment on the Mathematical ability of a private school students. Data showed that private school students have a knowledge ability level of $84.28 \%$, comprehension ability level of $82.58 \%$, and application ability level of $77.57 \%$, giving a Mathematical performance of $81.19 \%$. Using Multiple Regression Analysis, results showed that the application ability of the student is the highest predictor of his Mathematical performance, while the comprehension ability of the student is the least predictor his Mathematical performance.

If the previous paper focused on the knowledge, comprehension and application ability of private high school students, this present paper includes analysis, the fourth level of thinking skill in Bloom's Taxonomy. While the previous year respondents include grade 6 , third year and fourth year students, this present study includes the grade 5 students, thus making the population bigger and the result of the study more conclusive.

\subsection{Statement of the Problem}

This research focused on knowing the level of Mathematical ability of the students of a private school.

Specifically, it sought answers to the following questions:

- What is the mean level of Mathematical ability of the private high school students in terms of the following areas?
a.) knowledge;
b.) comprehension;
c.) application; and
d.) analysis

- What is the mean level of Mathematical performance of a private school students?; and

- Do the areas of Mathematical ability significantly affect the Mathematical performance of private school students?

- Is there a significant predictability of the Mathematical performance of private school students? Which of the three areas is the highest predictor? the least predictor?

\subsection{Significance of the Study}

Through this study, the following group of persons will be benefited:

Math teachers - Teachers play crucial role in training the minds of the students to be logically correct and critically active. Through their proper guidance, average students can do better and mathematically inclined students can do more.

School Officials - The needs of the teachers and the students should be properly relayed to school officials because the mission and vision of the school towards quality education and character building can only be achieved of the school officials, the teachers and parents will go hand-in-hand in working for the students.

Students - Result of the research done by the guidance office two years ago revealed that study habit has something to do with the academic performance of the students. Strengthening the areas which are weak can be achieved with good study habit which is performed inside the school and continued at home, of course with the support of the parents. 
Parents - Good environment and encouragement at home is expected as the students strive to do better in school. Emotional support is important as education is not only for the mind, but also for the heart and soul.

Readers and Researchers - As the research last school year has been beneficial towards the accomplishment of this present one, so this paper may initiate another study related to this.

\subsection{Scope and Limitation}

The students involved in this study are only grade 5, 69 and 10. Grade 5 students are taking up basic math, geometry, measurements and graphs. Grade 6 students are taking up basic math, integers and preparatory algebra. Grade 1 students are taking up geometry, trigonometry and statistics. Grade 10 students are taking up Advanced Algebra with Analytic Geometry and Preparatory Calculus. Final Exams in Math 5, Math 6, Geometry, Trigonometry, Advanced Algebra and Pre-Calculus will be used as research instruments in gathering data needed to answer the problem posed at the beginning of the study.

The Bloom's Taxonomy of educational objectives in cognitive domain enlists six levels: knowledge, comprehension, application, analysis, synthesis and evaluation. This paper focused only on the three levels: knowledge, comprehension, application and analysis.

\section{Review of Related Literature and Studies}

This portion presents related literature and studies that are relevant and will give light to the present study. Included also in this chapter are the hypotheses, the paradigm of the study and the definition of terms used on the pages of this paper.

\subsection{Mathematical Performance}

In the article written by Griffiths (2000), the author advocated that the teacher's major business is to produce changes in students. The changes brought about are viewed as students' performance and achievement, and this can be seen in the result of test and evaluation. School administrators and teachers alike believe that through evaluation and achievement testing, the extent of learning that has taken place and effectiveness of teaching can be gauged (Velasco, 1998). This means that evaluation and testing does not only benefit the students, but also the teacher as well.

This view and purposes of evaluation and testing as related to mathematical performance is a help to the present study as it underlines the fact that mathematical performance is a reflection of what the students have learned and how effective the teacher has gone far in the teaching process.

\subsection{Mathematical Ability}

In the article written by Chua (2006), he enlisted the different mathematical abilities that the students must possess, and they are the following:

1. Observative Ability- the ability to recognize quickly the "number" or "figure" represented by an object and connects this to a mathematical figure and relation.

2. Associative Ability- based on the mathematical ability of association as the process of forming connections between relevant ideas and/or knowledge.

3. Computational Ability- the ability to memorize the definitions, formulas and rules of operations; simplify an operational process; reverse a computational process and be able to check it; predict and estimate values; and recognize recurrence and induction.

4. Abstractive Summary Ability- This math ability requires students to summarize a particular problem; generate an abstract conclusion through analysis and synthesis; and apply the conclusion to the specific problem. 
5. Ability of Logical Reasoning- This ability is the core of mathematical abilities and includes 175 understanding and mastery of the relationship among formulas, principles, theorems, and axioms in a conceptual system; mastery of relevant logical knowledge such as sufficient and necessary condition, inductive reasoning, deductive reasoning and analogical reasoning; mastery of commonly used mathematical methods such as analytical, synthetic, inductive and reductive methods; and capacity to think in a concise manner by simplifying the reasoning process.

6. The ability of writing and expressing oneself- the ability to express ideas clearly and accurately such as in the presentation of solutions to problems.

Linking these mathematical abilities to the Bloom's Taxonomy, we can say that the observative ability pertains to knowledge level, the associative ability to comprehension level, the computational ability to application level, and the abstractive summary ability to analysis level. This strengthens the concepts presented in this paper because the Mathematical abilities presented in the article of Chua (2006) are related to the Mathematical abilities presented in this paper.

The Old Version of Bloom's Taxonomy of Educational Objectives has the following line up of level of thinking skills: knowledge, comprehension, application, analysis, synthesis and evaluation. But in Wikipedia Free Encyclopedia (2007), we can see a revised one:

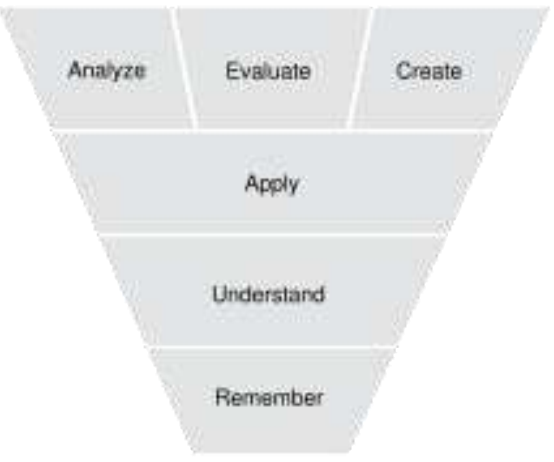

Fig. 1 The Revised Bloom's Taxonomy

We can see from the revised version that the knowledge level and comprehension level are replaced by remember and understand. In concept, they are actually the same. The figure shows that remember, understand and apply belongs to lower level of thinking skills, while analyze, evaluate (replacement for synthesis in the old version) and create (replacement for evaluate in the old version) belongs to a higher level of thinking skills.

\subsection{Knowledge}

Forehand (2005) in her revised model of Bloom's Taxonomy wrote that remembering includes retrieving, recognizing, and recalling relevant knowledge from long-term memory.

In the article written by Clark (1999), knowledge is recall of data or information. Examples are reciting a policy, quoting prices from memory to a customer, and knowing the safety rules. The key words related to this are defines, describes, identifies, knows, labels, lists, matches, names, outlines, recalls, recognizes, reproduces, selects and states.

\subsection{Comprehension}

The comprehension level according to Forehand (2005) involves the ability to construct meaning from oral, written, and graphic messages through interpreting, exemplifying, classifying, summarizing, inferring, comparing, and explaining. 
Clark (1999) states knowledge as understanding the meaning, translation, interpolation, and interpretation of instructions and problems. Examples are stating a problem in one's own words, rewriting the principles of test writing, explaining in one's own words the steps for performing a complex task, and translating an equation into a computer spreadsheet. The key words related to this are comprehends, converts, defends, distinguishes, estimates, explains, extends, generalizes, gives, infers, interprets, paraphrases, predicts, rewrites, summarizes and translates.

\subsection{Application}

According to Forehand (2005), applying means carrying out or using a procedure through executing, or implementing.

Clark (1999) states application as use of concept in a new situation or unprompted use of an abstraction. Examples are applying what was learned in the classroom into novel situations in the work place, using a manual to calculate an employees' vacation time, and applying laws of statistics to evaluate the reliability of a written test. The key words related to this are applies, changes, computes, constructs, demonstrates, discovers, manipulates, modifies, operates, predicts, prepares, produces, relates, shows, solves and uses.

\subsection{Analysis}

Forehand (2005) equates analysis to breaking of material into constituent parts, determining how the parts relate to one another and to an overall structure or purpose through differentiating, organizing, and attributing.

On the other hand, Clark (1999) wrote that analysis means separating material or concepts into component parts so that its organizational structure may be understood. It also means distinguishing between facts and inferences. Examples are troubleshooting a piece of equipment by using logical deduction, recognizing logical fallacies in reasoning, and gathering information from a department and selecting the required tasks for training. The key words related to this are analyzes, breaks down, compares, contrasts, diagrams, deconstructs, differentiates, discriminates, distinguishes, identifies, illustrates, infers, outlines, relates, selects and separates.

The above-mentioned readings on knowledge, comprehension and application level of thinking skill are important to the present study especially in formulating the instrument that were used in obtaining data for this research.

\subsection{Hypotheses}

As tentative solution to the problems posed at the beginning of this research, the following hypotheses were made:

1.) The four areas of Mathematical ability have no significant effect to the Mathematical performance of private school students.

2.) There is no significant predictability of the Mathematical performance of private school students.

\section{Figure 2. Paradigm}

\section{IV}

\begin{tabular}{|c|}
\hline Areas of Mathematical Ability \\
- Knowledge \\
- Comprehension \\
- Application
\end{tabular}

DV Mathematical Performance
(Percent Score on Final Exam)

Frame 2 
Figure 2 shows the paradigm of the study. It is composed of Frame 1 showing the independent variables and Frame 2 showing the dependent variable. The independent variable is the areas of Mathematical Ability which is subdivided into knowledge, comprehension, application and analysis. It is connected to the dependent variable (Mathematical Performance) to depict possible effect of one or more factors from the independent variable.

\subsection{Definition of Terms}

Mathematical Performance - According to New Lexicon Webster's Dictionary, this pertains to what is accomplished. Also, it is the effectiveness of the way somebody does his or her work (Microsoft Encarta 2005). In this present study, mathematical performance is the achievement of the students through written works. It is measured using the final exam given to the students this school year 2006-2007.

Mathematical Ability - According to Chua (2006), Mathematical ability is the ability to perform appropriate mental calculation and mathematical operations as well as effective prediction by using numbers, clues and signs. Mathematical ability in this study is the ability to recall information, to understand how the facts are related to each other and the ability to apply them to solve situations involving numbers and figures. It is measured using the individual percentage of scores in the knowledge part, comprehension part and application part of the final exam given to the students this school year 2006-2007.

Knowledge - Microsoft Encarta (2005) defines knowledge as information in mind: general awareness or possession of information, facts, ideas, truths, or principles. Knowledge in this study is the recall of information, concepts, formulas and theorems taught to the students for the school year 2006-2007. The knowledge part in the self-made test for the final exam of the students was used to determine the knowledge level of the students.

Comprehension - Microsoft Encarta (2005) defines comprehension as the understanding: the grasping of the meaning of something. Comprehension in this study is the understanding of how facts are related to each other, translating mathematical symbols into meaningful words and predicting the outcome of an event through the knowledge available. The comprehension part in the self-made test for the final exam of the students was used to determine the comprehension level of the students.

Application - Microsoft Encarta (2005) defines application as the use of something or the process of putting something into use. Application in this study is the ability to apply gained knowledge and understanding of concepts, formulas and theorems in solving situations involving numbers and figures. The application part in the self-made test for the final exam of the students was used to determine the application level of the students.

Analysis - Microsoft Encarta (2005) defines analysis as the separation of something into its constituents in order to find out what it contains, to examine individual parts, or to study the structure of the whole. Analysis in this study is the ability to list down or enumerate the parts of the whole and to be able to compare or differentiate each one from the other in relation to the components as a whole. The analysis part in the self-made test for the final exam of the students was used to determine the analysis level of the students.

\section{Research Design and Methodology}

This chapter discusses the nature of the study, how many students were included in the study, how the research proceeded, what instruments were used to gather data, and what statistical tool was used to obtain a meaningful result from the data gathered.

\subsection{Research Design}

This study employed a quasi-experimental design in which respondents have undergone a school year of teaching. Within that span of time, they have been acquainted in a nature of exam containing knowledge part, comprehension part, application part and analysis part for this was the nature of monthly and 
quarterly exams given to them. In the end, as their final exam, they needed to answer a self-made test to ${ }^{155 N: 2708-3578 \text { (0nthine) }} 175$ measure what they have learned and to gather data needed for the study.

\subsection{Population}

Students who have undergone the study were the grade five, six, nine and ten students of a private school. They were the students whom the researcher teach math subjects. The grade five was composed of 18 students, grade six was 19 , the grade 9 was 12 , and the grade 10 was 15 . A total of 64 students composed the population for this study.

\subsection{Data Gathering Procedure}

Gathering of data for this study consisted of the following steps:

- Copy of the final exam was submitted to the principal's office two weeks before the scheduled date of the final exam;

- Math exams for grades six and ten were administered last March 18 and 19, while Math exams for grades five and nine were administered last March 25 and 26;

- Test papers were gathered and checked; and

- The total score and the breakdown of scores for the knowledge part, comprehension part, application part and analysis part were properly recorded.

\subsection{Data Gathering Instrument}

The test questions were constructed in a multiple-choice type. Equal number of items was given to the four parts of the exam: 20 items for the knowledge part, 20 items for the comprehension part, 20 items for the application part, and 20 items for the analysis part, making a total of 80 items.

$$
\begin{array}{ll}
\text { Test I. Knowledge } & -20 \text { items } \\
\text { Test II. Comprehension } & -20 \text { items } \\
\text { Test III. Application } & -20 \text { items } \\
\text { Test IV. Analysis } & -\underline{20 \text { items }} \\
\multicolumn{1}{c}{\text { Total }} & -80 \text { items }
\end{array}
$$

The knowledge part contains questions which allow students to recall information, concepts, formula and theorems. The comprehension part contains questions that measure students' understanding of the concepts learned, and a little bit of computation to test their knowledge of using the formula (but not in word problems). The application part contains questions which test students' ability in applying the concepts and formulas learned in solving word problems. The analysis part contains questions that elicit students' ability to compare, differentiate and reason out.

\subsection{Statistical Treatment}

To probe the validity of the hypotheses given at the beginning of the study, the Regression analysis tool was used. This tool performs linear regression analysis by using the "least squares" method to fit a line through a set of observations. Through this, an analysis can be made on how the students' Mathematical performance is affected by one or more of the four areas of Mathematical ability. Also, students' performance can also be predicted through the apportioned share of effect of these four areas of Mathematical ability.

\section{Presentation, Interpretation and Analysis of Results}

This chapter presents the data gathered in graphical and table form. Interpretation and analysis follow after each presentation. 


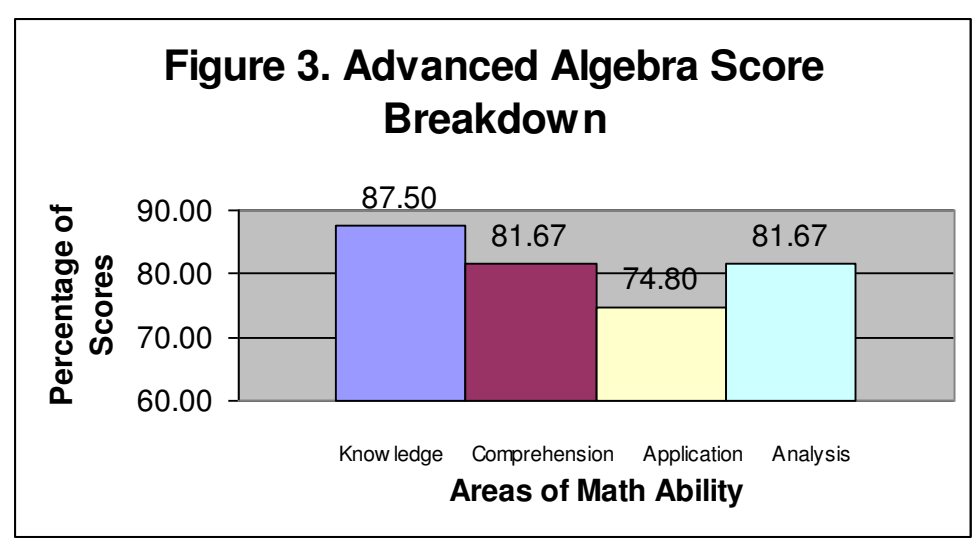

Figure 3 shows the breakdown of scores of the grade 10 students in fourth areas of Math ability, specifically in Advanced Algebra. In knowledge part, they have an average correct answer of 15.00 out of 20 items, resulting to $87.50 \%$ in knowledge level. In comprehension part, they have an average correct answer of 12.67 out of 20 items, resulting to $81.67 \%$ in comprehension level. In application part, they have an average correct answer of 9.87 out of 20 items, resulting to $74.80 \%$ in application level. In analysis part, they have an average correct answer of 12.67 out of 20 items, resulting to $81.67 \%$ in analysis level. The overall Mathematical performance of the fourth year students in Advanced Algebra is $81.38 \%$. The graph shows that the fourth year students were having difficulty when it comes to applying the concepts they've learned. They have knowledge and understanding of the subject matter but the problem solving part is difficult for them. Nevertheless, they can analyze Mathematical situations and problems.

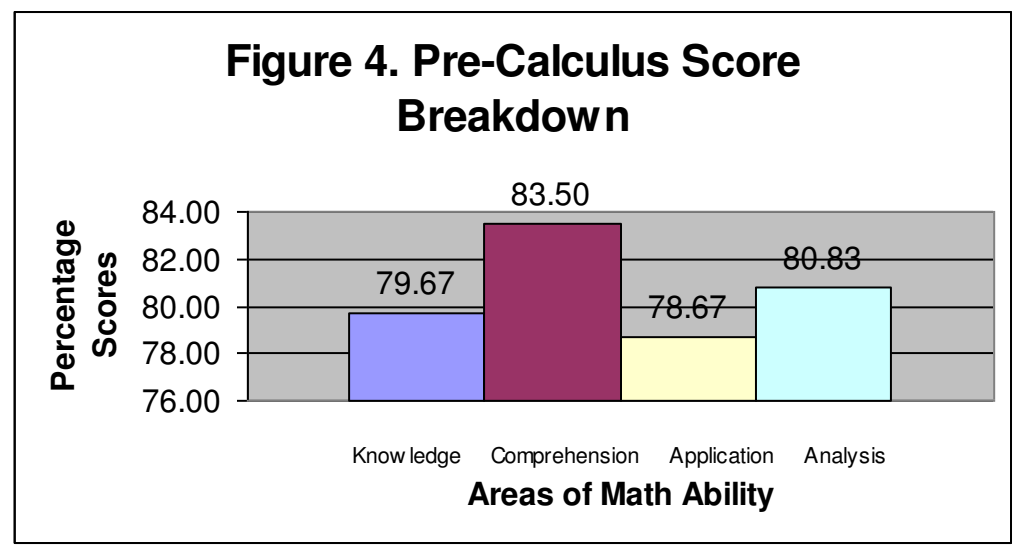

Figure 4 shows the breakdown of scores of the grade 10 students in four areas of Math ability, specifically for Pre-Calculus. In knowledge part, they have an average correct answer of 11.87 out of 20 items, resulting to $79.67 \%$ in knowledge level. In comprehension part, they have an average correct answer of 13.40 out of 20 items, resulting to $83.50 \%$ in comprehension level. In application part, they have an average correct answer of 11.47 out of 20 items, resulting to $78.67 \%$ in application level. In analysis part, they have an average of 12.33 out of 20 items, resulting to $80.83 \%$ in analysis part. The overall Mathematical performance of the fourth year students in Pre-Calculus is $80.67 \%$. The graph shows that the fourth year students were having difficulty when it comes to applying the concepts they've learned. They have knowledge and understanding of the subject matter but the problem solving part is difficult for them. Nevertheless, they can analyze Mathematical situations and dissect parts in Mathematical problems. 


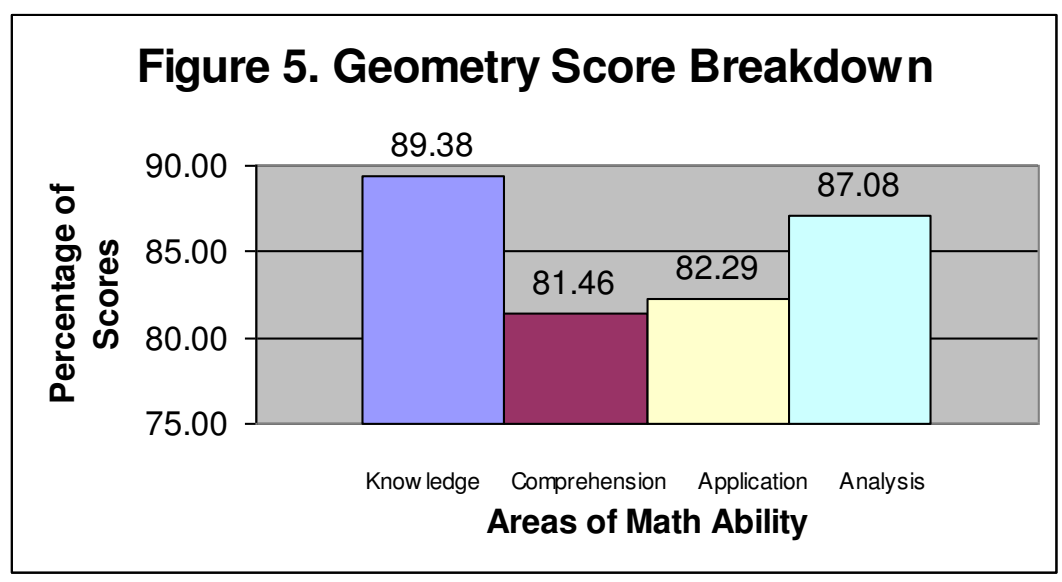

Figure 5 shows the breakdown of scores of the grade 9 students in four areas of Math ability, specifically for Geometry. In knowledge part, they have an average correct answer of 15.75 out of 20 items, resulting to $89.38 \%$ in knowledge level. In comprehension part, they have an average correct answer of 12.58 out of 20 items, resulting to $81.46 \%$ in comprehension level. In application part, they have an average correct answer of 12.92 out of 20 items, resulting to $82.29 \%$ in application level. In analysis part, they have an average correct answer of 14.83 out of 20 items, resulting to $87.08 \%$ in analysis level. The overall Mathematical performance of the third year students in Geometry is $85.05 \%$. The graph shows that the third year students were having difficulty in understanding the concepts they've learned. This accounts for their low score also in application part though they have memorized concepts and can distinguish different theorems, laws and facts related to Geometry.

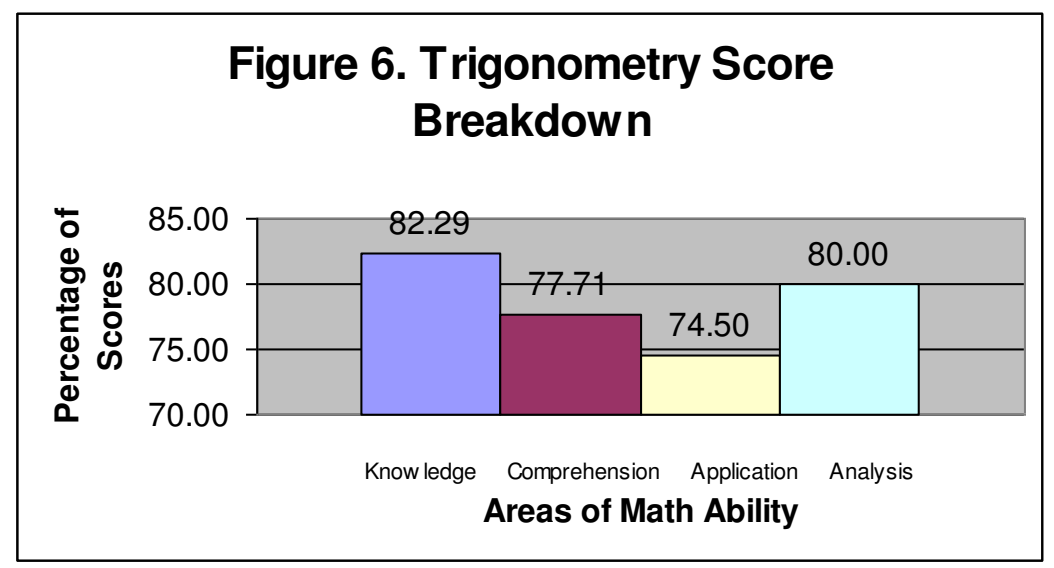

Figure 6 shows the breakdown of scores of the grade 9 students in four areas of Math ability, specifically for Trigonometry. In knowledge part, they have an average correct answer of 12.92 out of 20 items, resulting to $82.29 \%$ in knowledge level. In comprehension part, they have an average correct answer of 1.08 out of 20 items, resulting to $77.71 \%$ in comprehension level. In application part, they have an average correct answer of 9.67 out of 20 items, resulting to $74.50 \%$ in application level. In analysis part, they have an average correct answer of 12.00 out of 20 items, resulting to $80.00 \%$ in analysis part. The overall Mathematical performance of the third year students in Trigonometry is $78.54 \%$. The graph shows that the third year students were having difficulty when it comes to applying the concepts they've learned. They have 


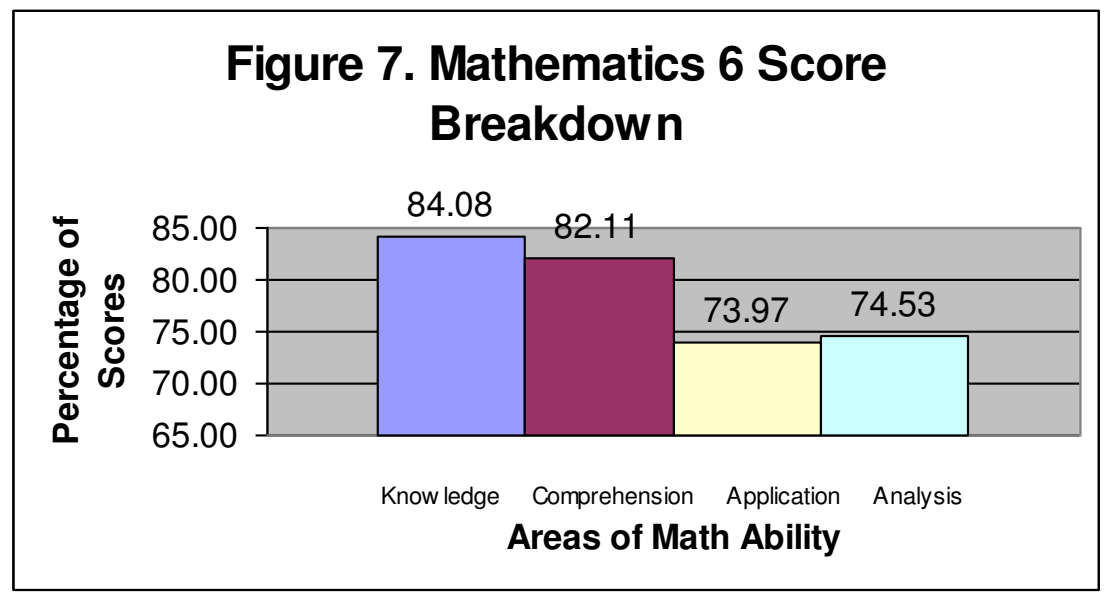

Figure 7 shows the breakdown of scores of grade 6 students in four areas of Math ability. In knowledge part, they have an average correct answer of 13.63 out of 20 items, resulting to $84.08 \%$ in knowledge level. In comprehension part, they have an average correct answer of 12.84 out of 20 items, resulting to $82.11 \%$ in comprehension level. In application part, they have an average correct answer of 9.32 out of 20 items, resulting to $73.97 \%$ in application level. In analysis part, they have an average correct answer of 9.68 out of 20 items, resulting to $74.53 \%$ in analysis level. The overall Mathematical performance of the grade 6 students is $78.42 \%$. The graph shows that the grade 6 students were having difficulty when it comes to applying the concepts they've learned and in analyzing Mathematical situations and problems. They have knowledge and understanding of the subject matter but they were having hard time using those concepts in real life and in analyzing the learned facts on how they fit and relate to each other.

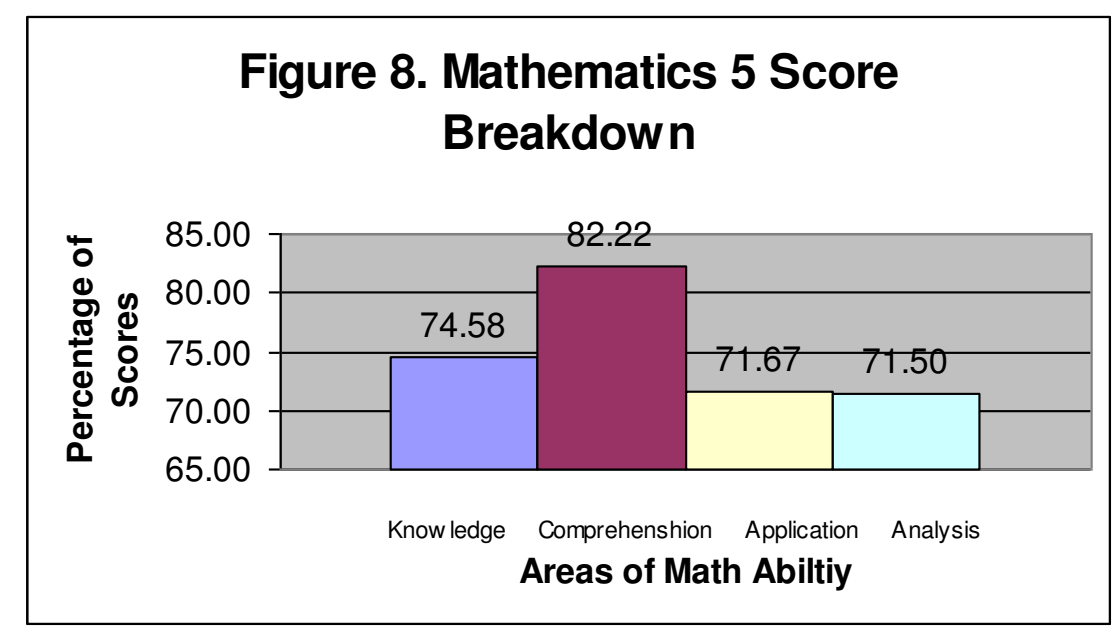

Figure 8 shows the breakdown of scores of grade 5 students in four areas of Math ability. In knowledge part, they have an average correct answer of 9.72 out of 20 items, resulting to $74.58 \%$ in knowledge level. In comprehension part, they have an average correct answer of 12.89 out of 20 items, 
resulting to $82.22 \%$ in comprehension level. In application part, they have an average correct answer of 7.78 out of 20 items, resulting to $71.67 \%$ in application level. In analysis part, they have an average correct answer of 7.67 out of 20 items, resulting to $71.50 \%$ in analysis level. The overall Mathematical performance of the grade 6 students is $74.27 \%$. The graph shows that the grade 5 students were having difficulty when it comes to applying the concepts they've learned and in analyzing Mathematical situations and problems. They have knowledge and high understanding of the subject matter but they were having hard time using those concepts in real life and in analyzing the learned facts on how they fit and relate to each other.

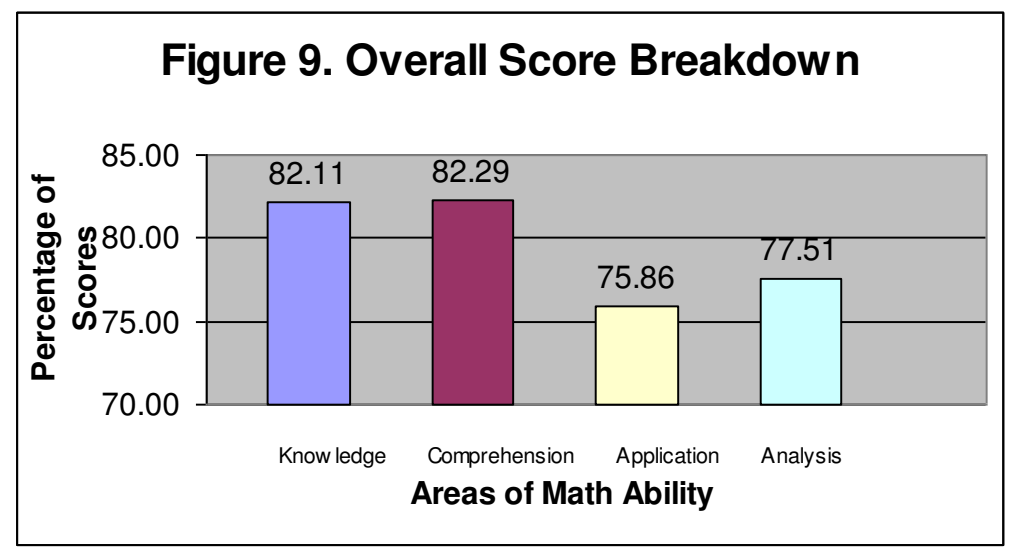

Figure 9 shows the overall breakdown of scores of grade 5, 69 and 10 students in four areas of Math ability. In knowledge part, they have an average correct answer of 12.84 out of 20 items, resulting to $82.11 \%$ in knowledge level. In comprehension part, they have an average correct answer of 12.92 out of 20 items, resulting to $82.29 \%$ in comprehension level. In application part, they have an average correct answer of 10.34 out of 20 items, resulting to $75.86 \%$ in application level. In analysis part, they have an average correct answer of 11.00 out of 20 items, resulting to $77.51 \%$ in analysis level. The overall Mathematical performance of the grade six, third year and fourth year students is $79.07 \%$. The graph shows that the students were having difficulty when it comes to applying the concepts they've learned. They have knowledge and understanding of the subject matter but the problem solving part is difficult for them. Their low level of analysis ability supports their difficulty in applying what they've learned.

Table 1. Mathematical Performance of a Private School

\begin{tabular}{|l|c|}
\hline Grade/Year Level & Final Exam Mean Percent Score \\
\hline Fourth Year (Advanced Algebra) & 81.38 \\
Fourth Year (Pre-Calculus) & 80.67 \\
Third Year (Geometry) & 85.05 \\
Third Year (Trigonometry) & 78.54 \\
Grade 6 & 78.42 \\
Grade 5 & 74.27 \\
\hline \multicolumn{2}{|c|}{ Overall Mean } \\
\hline
\end{tabular}

Table 1 shows the Mathematical performance of private school students in different fields of Mathematics. Grade 10 students have a mean percent score of $81.38 \%$ in Advanced Algebra and $80.67 \%$ in Pre-Calculus. These gave the fourth year students an average of $81.03 \%$ for the two subjects. Grade 9 students have a mean percent score of $85.05 \%$ in Geometry and $78.54 \%$ in Trigonometry. These gave the third year 
while grade 5 students have a mean percent score of $74.27 \%$. For the overall mean, the private school students have a Mathematical performance level of $79.07 \%$.

This low mean level can be accounted to the fact that majority of the students are average and below average when it comes to Mathematical performance. There are but few students who are above average in Mathematical performance.

The low achievement of the students can also be attributed to the poor study habits. The study of Camahalan (2006) confirms that students as active agents of their behaviors can be trained to be responsible learners and thus acquire the goal of life-long education which is learning not just what to learn but more importantly how to learn.

Table 2. Summary Output of Regression Analysis for the Private School Students' Mathematical Performance

\begin{tabular}{|c|c|c|c|c|c|}
\hline \multicolumn{6}{|c|}{ SUMMARY OUTPUT } \\
\hline \multicolumn{2}{|c|}{ Regression Statistics } & & & & \\
\hline Multiple R & 0.998881545 & & & & \\
\hline R Square & 0.997764341 & & & & \\
\hline Adjusted R Square & 0.997612771 & & & & \\
\hline Standard Error & 0.342104457 & & & & \\
\hline Observations & 64 & & & & \\
\hline \multicolumn{6}{|l|}{ ANOVA } \\
\hline & df & SS & MS & $\mathrm{F}$ & Significance F \\
\hline Regression & 4 & 3081.711119 & 770.4277797 & 6582.857716 & $1.95354 \mathrm{E}-77$ \\
\hline Residual & 59 & 6.905092129 & 0.11703546 & & \\
\hline \multirow[t]{2}{*}{ Total } & 63 & 3088.616211 & & & \\
\hline & Coefficients & Standard Error & t Stat & $\mathrm{P}$-value & \\
\hline Intercept & -1.63821385 & 0.519891362 & -3.15106957 & 0.002555247 & \\
\hline X Variable 1 & 0.229952345 & 0.007907877 & 29.07889928 & $1.13172 \mathrm{E}-36$ & \\
\hline $\mathrm{X}$ Variable 2 & 0.227004121 & 0.00663752 & 34.20014205 & $1.3397 \mathrm{E}-40$ & \\
\hline $\mathrm{X}$ Variable 3 & 0.289455474 & 0.008690856 & 33.30574909 & $5.93098 \mathrm{E}-40$ & \\
\hline $\mathrm{X}$ Variable 4 & 0.273435606 & 0.008114671 & 33.69645136 & $3.08301 \mathrm{E}-40$ & \\
\hline
\end{tabular}

$\alpha=\mathbf{0 . 0 5}$

The Regression Model $\Rightarrow \hat{Y}=-1.638+0.230 X_{1}+0.227 X_{2}+0.289 X_{3}+0.273 X_{4}+0.342$

Table 2 shows the summary output of regression analysis for UECS students' mathematical performance. The value of $F$ for this study is 6,582.858, with a Significance F of $1.5 \times 10^{-77}$ which is less than $\alpha=0.05$. On the basis of this information, the first hypothesis that the four areas of Mathematical ability have no significant effect to the Mathematical performance is rejected. That is, the four areas of Mathematical ability have significant effect to the Mathematical performance of the private school students. The R square of 0.998 and the Adjusted R Square of 0.998 for this regression analysis are almost equal to 1 (100\%). This means that $100 \%$ of the variation in the Mathematical performance is accounted for by the four areas of Mathematical ability.

The $\mathrm{P}$-value for knowledge is $1.132 \times 10^{-36}$, comprehension is $1.340 \times 10^{-40}$, application is $5.931 \times$ $10^{-40}$, and analysis is $3.083 \times 10^{-40}$. All of these values are less than $\alpha=0.05$. On the basis of this information, the second hypothesis that there is no significant predictability of the Mathematical performance of students is 


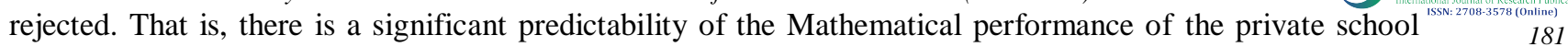
students.

For the regression model, -1.638 is the constant, 0.230 is the coefficient for knowledge, 0.227 is the coefficient for comprehension, 0.289 is the coefficient for application, 0.273 is the coefficient for analysis, and 0.342 is the standard error of estimate. The model indicates that for every 1 unit (1\%) increase in the knowledge part, the predicted Mathematical performance $(\hat{Y})$ increases by 0.230 , if the comprehension, application and analysis parts are held constant. For every 1 unit (1\%) increase in the comprehension part, $\hat{Y}$ increases by 0.227 , if the knowledge, application and analysis parts are held constant. For every 1 unit $(1 \%)$ increase in the application part, $\hat{Y}$ increases by 0.289 , if the knowledge, comprehension and analysis parts are held constant. Also, for every 1 unit (1\%) increase in the analysis part, $\hat{Y}$ increases by 0.273 if the knowledge, comprehension and analysis parts are held constant.

If $\mathrm{X}_{1}$ (knowledge) is $88, \mathrm{X}_{2}$ (comprehension) is $85, \mathrm{X}_{3}$ (application) is 80 , and $\mathrm{X}_{4}$ (analysis) is 76 , the model predicts that the Mathematical performance of the student in the final exam is 82.11 .

$$
\begin{aligned}
\hat{Y} & =-1.638+0.230(88)+0.227(85)+0.289(80)+0.273(76)+0.342 \\
& =82.11
\end{aligned}
$$

Comparing the P-values of knowledge, comprehension and application, the application part of the exam can be deemed the highest predictor, while the knowledge part is the least predictor. This means that if the student is good in application when it comes to Math, there is a high possibility of having good performance in Math. On the other hand, if the student is good in knowledge ability, it does not assure good mathematical performance for he still needs to apply it in solving problems to prove that he really understands the concept behind. The application part being the highest predictor of the students' Mathematical ability supports Howard Gardner's definition of intelligence, that is, the application of the things learned. An intelligent person is who knows how to apply what he learned from others and from his own experience, too.

\section{Summary of Findings, Conclusion and Recommendation}

This chapter enumerates the findings of this study, the conclusion that answers the specific questions posed at the beginning of the study, and the recommendation addressed to group of persons.

\subsection{Summary of Findings}

Using the final exam as the instrument to gather data for this study, the grade 10 students in their Advanced Algebra subject obtained $87.50 \%$ for knowledge, $81.67 \%$ for comprehension, $74.80 \%$ for application, and $81.67 \%$ for analysis. In their Pre-Calculus subject, they obtained $79.67 \%$ for knowledge, $83.50 \%$ for comprehension, $78.67 \%$ for application, and $80.83 \%$ for analysis. The third year students in their Geometry subject obtained $89.38 \%$ for knowledge, $81.46 \%$ for comprehension, $82.29 \%$ for application, and $87.08 \%$ for analysis. In their Trigonometry subject, they obtained $82.29 \%$ for knowledge, $77.71 \%$ for comprehension, $74.50 \%$ for application, and $80.00 \%$ for analysis. The grade 6 students in their Mathematics subject obtained $84.08 \%$ for knowledge, $82.11 \%$ for comprehension, $73.97 \%$ for application, and $74.53 \%$ for analysis. The grade 5 students in their Mathematics subject obtained $74.58 \%$ for knowledge, $82.22 \%$ for comprehension, $71.67 \%$ for application, and $71.50 \%$ for analysis.

The mean level of Mathematical performance of grade 10 students is $81.03 \%$, third year students $81.80 \%$, grade 6 students $78.42 \%$, and grade 5 students $74.27 \%$.

Using $\alpha=0.05$ in the Regression analysis, the Significance F obtained is $1.5 \times 10^{-77}$. The P-value for knowledge is $1.132 \times 10^{-36}$, for comprehension $1.340 \times 10^{-40}$, for application $5.931 \times 10^{-40}$, and for analysis $3.083 \times 10^{-40}$. Application has the lowest P-value while knowledge has the greatest P-value.

\subsection{Conclusion}

The following statements answer the specific questions made at the beginning of the study:

- The mean level of Mathematical ability of the private school students 
d. in terms of analysis is $77.51 \%$.

- The mean level of Mathematical performance of private school students is $79.07 \%$.

- Using the regression analysis, since the Significance F $=1.5 \times 10^{-77}$ is less than $\alpha=0.05$, the first hypothesis is rejected. This means that the areas of Mathematical ability significantly affect the Mathematical performance of private school students.

- Since the P-values of knowledge, comprehension, application and analysis are all less than $\alpha=$ 0.05 , the second hypothesis is rejected. This means that there is a significant predictability of the Mathematical performance of private school students. The highest predictor of students' Mathematical performance is the application ability of the student, while the least predictor is the knowledge ability of the student.

\subsection{Recommendation}

The write up of Nebres and Lee-Chua (2007) sighted eight strengths of Filipino-Chinese Math Culture that need to be strengthened. Six out of eight of those strengths are applicable here as recommendations directed toward students, parents and teachers.

- Peer influence. For students, those having difficulty learning how to apply the concepts of Mathematics should associate themselves with those inclined to it. Teachers also should make use of group dynamics and peer tutoring to enable the students to deeply grasp the lessons. Learning from the teacher and from their peer doubles the benefit and the result of learning is strengthened.

- Confucian tradition. "The Confucian tradition of learning, though not as strong in the Philippines as in many parts of Asia, is still adhered to by older-generation Chinese immigrants, who believe that hard work and discipline are the key to success in a new world." Students should always be reminded of the value of discipline and good study habit. Mathematics is not learned by memorization but by constant drill and practice.

- Extensive parental support. "Parents of successful students consistently supervise homework, provide references, mandate routine and place of study, and are constantly physically present in their children's lives." Parents are indispensable part of the learning process of a child. What can be learned from the school can be reinforced at home by close guidance and follow up.

- Early exposure. "Most good problem solvers report having been fascinated with math since childhood, and such curiosity has led them to explore harder problems on their own." As early as preschool years, parents at home can expose the child to the world of numbers: jigsaw puzzles, time and clock drill, counting rhymes, and a lot more of exciting techniques.

- Mental toughness. "Mentally tough students believe that they are capable of solving the problem, focus on the task at hand, and possess a high frustration threshold." Students shall not easily give up when it is now time to apply the lessons thought in solving worded problems. They should have a positive view that in every problem, there is a solution.

- Excellent master teachers. "Experienced master teachers start by encouraging students, and end by challenging them." Math teachers should delve more on activities, questions and problems that challenges students' thinking and allows them to even go beyond what is taught to them.

\section{References}

Anderson, L. W., \& Krathwohl, D. R. (Eds.). (2001). “A Taxonomy for Learning, Teaching and Assessing: A Revision of Bloom's Taxonomy of Educational Objectives". Complete edition, New York : Longman.

Camahalan, Faye Marsha G. (September, 2006). Effects of self-regulated learning on mathematics achievement of selected Southeast Asian Children Journal of Instructional Psychology.

Chua, Simon L. (2006). "Challenging and Effective Teaching in Secondary Mathematics". Zamboanga Chong Hua High School.

Clark, Donald. (1999). "Learning Domains or Bloom's Taxonomy". 
Forehand, Mary. (2005). "Bloom's taxonomy: Original and Revised”. M. Orey (Ed.). Emerging Perspectives on Learning, Teaching, and Technology.

Griffiths, P. A. (March 28, 2008). "Mathematics at the Turn of the Millennium," American Mathematical Monthly, Vol. 7, Iss. 1, 2000, pp. 1-14. Manila Times. Education Department...

Microsoftß Encarta® Premium Suite. (2005).

Nebres, Bienvenido F., Lee-Chua, Queena N. (2007). Successful High-Level Problem Solving in the Philippines. Ateneo de Manila University, Philippines.

New Lexicon Webster's Dictionary

Velasco, Cecilia P. (1998). "Effects of Technology-Oriented Modular Instruction in Teaching English: Implication for Curriculum Development," Unpublished Masters Thesis, TUP, Manila.

Wikipedia. (2007). "Taxonomy of Educational Objectives". 